\title{
Assessment of Knowledge, Attitude and Practices (KAPS) of Anthrax among Pastoralists in Wajir, Isiolo and Marsabit Counties, Kenya
}

\author{
Abdirahim Mohamed $^{1}$, Gathura Peter Baaro ${ }^{2}$ and Shukri Jama Gelle ${ }^{1}$ \\ 1. IGAD Sheikh Technical Veterinary School and Reference Centre (ISTVS), Sheikh, Somalia, P.O. Box 74916, 00200, Nairobi, \\ Kenya
}

2. Department of Public Health, Pharmacology and Toxicology, University of Nairobi, Nairobi, Somalia, P.O. Box 29053, 00625, Nairobi, Kenya

\begin{abstract}
Anthrax is an important zoonotic disease in Kenya causing high morbidity and mortality in both human and livestock. It is endemic in the country. The objective of this study was to assess the knowledge, attitude and practices (KAPS) of anthrax among pastoralists in Wajir, Isiolo and Marsabit. The study was cross-sectional whereby various areas of anthrax outbreaks were identified through the veterinary departments in the three study counties of Wajir, Isiolo and Marsabit. These areas were visited and using systematic sampling methods, a total of 400 households were visited. Data were collected through questionnaires administered via personal interviews. Information collected included demographic characteristics of the households, knowledge on anthrax, attitude and practices on the disease. Pastoralists had adequate knowledge on anthrax. They correctly pointed out the clinical signs of anthrax in livestock such as sudden death, bleeding from body orifices and cutanous sores. The indigenous knowledge was uniform in all the three counties. Despite that knowledge, they reportedly engaged in dangerous practices that would expose them to infection by anthrax. These practices included consumption of meat from suspect anthrax cases, opening of carcasses of dead animals and throwing of anthrax suspect carcasses in bushes. Anthrax is a well known disease in this pastoral setting. There is a need for education programmes to be designed for this community especially with regard to proper handling of suspect anthrax cases. Continuous anthrax efforts should be initiated through vaccination of livestock.
\end{abstract}

Key words: Anthrax, KAPS, Kud, cutaneous sores.

\section{Introduction}

The main constraints hindering the productivity of the livestock sector in most sub-Saharan countries are diseases, poor nutrition, poor breeding policies and management. Anthrax is among the most common diseases in sub-Saharan countries and is caused by Bacillus anthracis, a gram positive and capsulated bacillus [1]. It is one of the neglected tropical diseases in Africa and besides its continuous outbreaks, there are limited studies on the dynamics and the risk factors of this disease.

Anthrax is a highly contagious and virulent disease

Corresponding author: Abdirahim Mohamed, MSc., research fields: veterinary public health and zoonosis.
[2]. It mainly affects herbivorous animals, although all mammals and some avian species are also susceptible to this disease. B. anthracis is a gram positive, rod-shaped and spore forming bacteria-produces this lethal sickness. It is per acute disease, death can occur within a short time, approximately $24 \mathrm{~h}$. As a result, those afflicted with the disease are largely found dead. This disease can be transmitted from infected animals including sheep, goats, cattle, pigs, buffaloes, or other wild animals to humans by direct or indirect contact with said animals and their by-products [3].

B. anthracis exists in two forms, vegetative cells (inside the host) and spores for persistence in the soil or environment [4]. Anthrax can be found naturally in 
soil and commonly affects domestic and wild animals around the world. It occurs in all food animals (cattle, sheep, goat, horse), which are susceptible to the organism. Pigs are more resistant than sheep and horse, where as dog and cats relatively resistant and birds are highly resistant [3]. With unvaccinated animals living in endemic regions, anthrax can be a serious disease. While the causative agent of anthrax can be found in many parts of the world, cases occur commonly only in specific geographic locations. Anthrax outbreaks often occur in localities which are known to have calcareous and alkaline soil, intermittent episodes of flooding and a warm environment [5].

There are endemic areas with more frequent outbreaks, while other areas are subject to intermittent outbreaks due to weather changes. This can in turn lead to anthrax spores, which were initially inactive in the soil, to rise into the surface of the ground. This causes herbivores grazing in such areas to swallow the spores. The spores then germinate inside the animals and subsequently the disease manifests [6].

Anthrax can be present in several different clinical forms, depending on the host factors, strain-specific factors and the route of infection. In herbivorous animals, anthrax usually occurs as an acute septicemia with a high fatality rate and is usually characterized by hemorrhagic lymphadenitis. In horses, pigs, dogs and humans, it is often less acute although still potentially fatal [1]. On the basis of route of infection, there are three clinical forms of anthrax such as cutaneous (skin), gastrointestinal (ingestion) and pulmonary through inhalation of spores [7].

Humans usually acquire the disease after close contact or proximity with infected animals or their products [8]. Anthrax is an occupational disease that can be found in wildlife, animal food, imported hides and skins, waste water from tanneries, contamination of indigenous pastures and livestock. In most situations, human anthrax cases occur only occasionally and intermittently.

In many areas of Africa, anthrax is an endemic disease. In Kenya, sporadic cases of anthrax are reported from all parts of the country, although most cases are reported in the former Rift Valley province and some central counties in Kenya. And based on the burden, socioeconomic impact, epidemic potential and severity of disease, it is ranked the number one zoonotic disease in Kenya [9]. In Northern Kenya, people practice pastoralism and move their animals in search of pasture and water. Due to this, there is inevitably frequent contact between wild animals and livestock.

In these areas, the ecology and distribution of $B$. anthracis is poorly understood despite the continuous cases found in humans, livestock and wildlife. Information remains scanty about the handling of live animals and carcass and the subsequent outbreaks. Unreliable reporting systems and poor diagnosis makes it challenging to estimate the true incidence of anthrax.

When anthrax occurs, it is usually associated with human deaths as a result of eating uninspected meat. In Northern Kenya, people practices a pastoral way of living in which they move their animals in search of pasture and water. Due to this, there is inevitably frequent contact between wild animals and livestock and anthrax cases in human, livestock and wild animals are continuously reported in these areas. The purpose of this study was to assess the knowledge, attitude and practices (KAPS) of anthrax among pastoralists in Wajir, Isiolo and Marsabit.

\section{Materials and Methods}

\subsection{Study Area}

This study was undertaken in Wajir, Marsabit and Isiolo counties of Kenya. These counties are some of the arid and semi-arid lands (ASALS) in Kenya. The communities living in these counties are pure pastoralists. These are inhabited mostly by the Somali, Gabra, Boran, Rendille, Sanburu, Turkana and Daasanach tribes among others. 


\subsection{Study Design}

The study was a questionnaire survey conducted between September 2016 and July 2017.

\subsection{Sample Size Determination}

The sample size for assessing the KAPS of anthrax was calculated using Yamane's formula [10] with standard error of $5 \%$ and confidence interval of 95\%:

$$
n=N /\left(1+N e^{2}\right)
$$

where $n$ is the sample size, $N$ is the population size, $e$ is the level of precision (or error limit).

\subsection{Data Collection}

A total number of 400 questionnaires were administered to 400 farmers who dwell in the areas within which anthrax outbreaks were confirmed. Farmers were selected using systematic sampling with an interval of five households. The household heads were selected for the questionnaires. Questionnaires were printed using English language and were translated to the different local languages with the help of local veterinary extension officers. Information regarding demographic characteristics, knowledge about anthrax, symptoms of anthrax in livestock, symptoms of anthrax in human and sources of anthrax outbreaks, was obtained. Information about attitudes and practices on anthrax, how they perceive anthrax, such as how to handle animals which with anthrax, slaughtering dead animals, slaughtering animals dead with anthrax, skinning of animals dead with anthrax, were collected.

\subsection{Data Analysis}

The data collected in the questionnaire surveys was recorded and analyzed with Stata (version 11). Descriptive statistics were generated and the results displayed in graphs and tables. The answers of the questions about knowledge and practices of anthrax were ordered as poor, moderate and good. The correct answer was coded as 1 and the wrong answer coded 0 , it was then summed up. The total responses of anthrax knowledge were ordered as $0-2=$ poor, $3=$ medium and 4-5 = good knowledge. The total responses on anthrax practices were ordered as $0-2=$ poor, $3-4=$ medium and 5-6 = good.

\section{Results}

\subsection{Demographic Characteristics of the Surveyed Population}

Almost two-thirds (67\%; 266/400) of the surveyed population were males (Table 1). Majority of the study population were in age-group of 45-58 years indicating that livestock ownership was mostly by the aged. Education was very low with three quarters (75.3\%) of the population having no formal education. Only $1.5 \%$ of the 400 of the surveyed population had university education.

A variety of livestock species were found in the surveyed households including sheep, goats, cattle, camels and chicken (Table 2). Goats, sheep and cattle were the most commonly kept species. Camel and donkeys were also popular but at a lower frequencies. These later species are very handy for ferrying household items when the pastoralists move to new areas in search of water and pasture for their livestock.

\subsection{Knowledge on Anthrax}

Anthrax was well known in the three counties considering the local names of the disease (Table 3). Indeed, most of the local names of the disease relate to the cutaneous form of anthrax. One ethnic group, the Gabra related anthrax to the soil.

Table 4 summarizes the level of anthrax knowledge in Wajir, Marsabit and Isiolo. The percentage of good anthrax knowledge was $57.7 \%$ for Wajir, $69.8 \%$ for Marsabit and 46.9\% for Isiolo.

Pastoralists reported anthrax as a zoonotic disease together with rabies, brucellosis and Rift Valley fever (Fig. 1). This was an indication that pastoralists have a wealth of indigenous knowledge on livestock diseases.

Various signs of anthrax in livestock were reported by pastoralists from the three counties, including 
Table 1 Demographic characteristics of the surveyed population of Marsabit, Isiolo and Wajir, Kenya, 2016-2017.

\begin{tabular}{llll}
\hline Variable & Level & Number & Proportion (\%) \\
\hline Sex & Male & 266 & 66.5 \\
& Female & 134 & 33.5 \\
\hline Total & & 400 & 100 \\
\hline Age-group (years) & $18-30$ & 75 & 19 \\
& $31-44$ & 108 & 27 \\
& $45-58$ & 111 & 28 \\
\hline Total & $>58$ & 106 & 26 \\
\hline Education & & 400 & 100 \\
& None & 301 & 75.2 \\
& Elementary & 38 & 9.5 \\
& Intermediate & 31 & 7.8 \\
& Secondary & 24 & 6 \\
\hline Total & University & 6 & 1.5 \\
\hline
\end{tabular}

Table 2 Livestock ownership in the surveyed households, 2016-2017.

\begin{tabular}{lllllll}
\hline County & Sheep & Goats & Cattle & Camel & Donkey & Chicken \\
\hline Wajir & $144(38 \%)$ & $142(37 \%)$ & $81(32 \%)$ & $74(52 \%)$ & $37(25 \%)$ & $10(17 \%)$ \\
Isiolo & $139(36 \%)$ & $139(36 \%)$ & $94(37 \%)$ & $25(18 \%)$ & $46(32 \%)$ & $49(80 \%)$ \\
Marsabit & $99(26 \%)$ & $102(27 \%)$ & $81(32 \%)$ & $42(30 \%)$ & $62(43 \%)$ & $2(3 \%)$ \\
\hline Total & 382 & 383 & 256 & 141 & 145 & 61 \\
\hline
\end{tabular}

Table 3 Traditional names of anthrax.

\begin{tabular}{ll}
\hline Ethnic & Local names of anthrax \\
\hline Gabra & Chilmale, Wuni Awara (disease of the soil) \\
Somali & Kud (cutaneous ulcers on the skin) \\
Daasanach & Gamudich \\
Boran & Lockshum (nodules on the skin) \\
Turkana & Enomokore \\
Rendille & Sugeri hara \\
\hline
\end{tabular}

Table 4 Level of anthrax knowledge in Wajir, Marsabit and Isiolo counties.

\begin{tabular}{llll}
\hline Level of anthrax knowledge & Wajir & Marsabit & Isiolo \\
\hline Poor & $15(10.1 \%)$ & $1(0.9 \%)$ & $21(14.5 \%)$ \\
Moderate & $48(32.2 \%)$ & $31(29.3 \%)$ & $56(38.6 \%)$ \\
Good & $86(57.7 \%)$ & $74(69.8 \%)$ & $68(46.9 \%)$ \\
\hline Total & 149 & 106 & 145 \\
\hline
\end{tabular}

sudden death, bleeding from natural orifices and skin nodules (Fig. 2). Sudden death was reported equally in the three counties while bleeding from orifices was reported by more pastoralists from Wajir and Marsabit counties (Fig. 2). Sudden death, skin nodules and bleeding from body orifices were reported as signs of anthrax in humans.

Modes of anthrax transmission to human are displayed in Table 5. However, some of the transmission modes were reported at higher frequencies than the others including consumption of infected animal products (320 respondents), contact with infected livestock (199 responds) (Table 5). Infected aerosols, an important mode of transmission for pulmonary form of anthrax were reported by 59 respondents. 


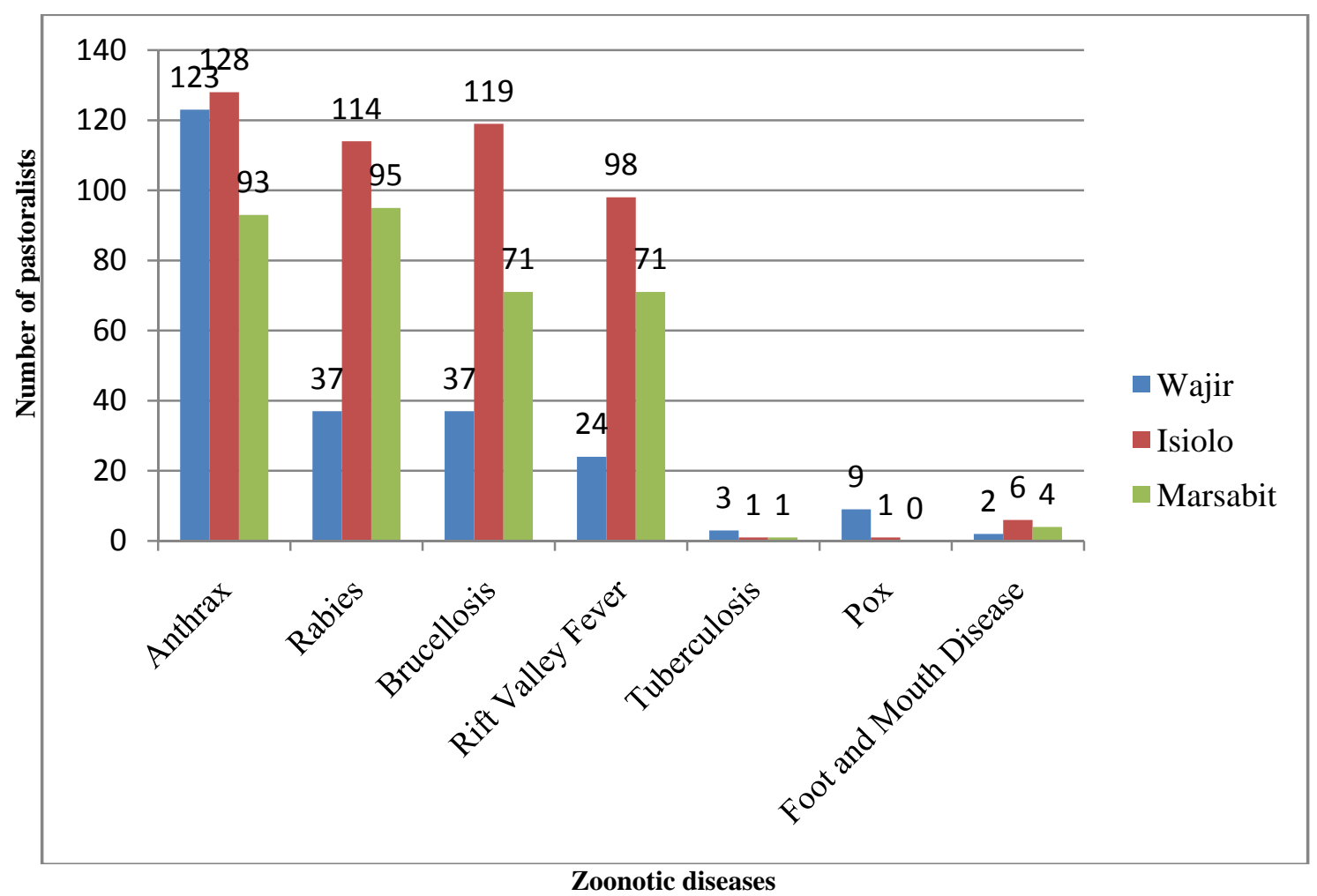

Fig. 1 Diseases perceived as zoonosis by the pastoralists of Wajir, Isiolo and Marsabit.

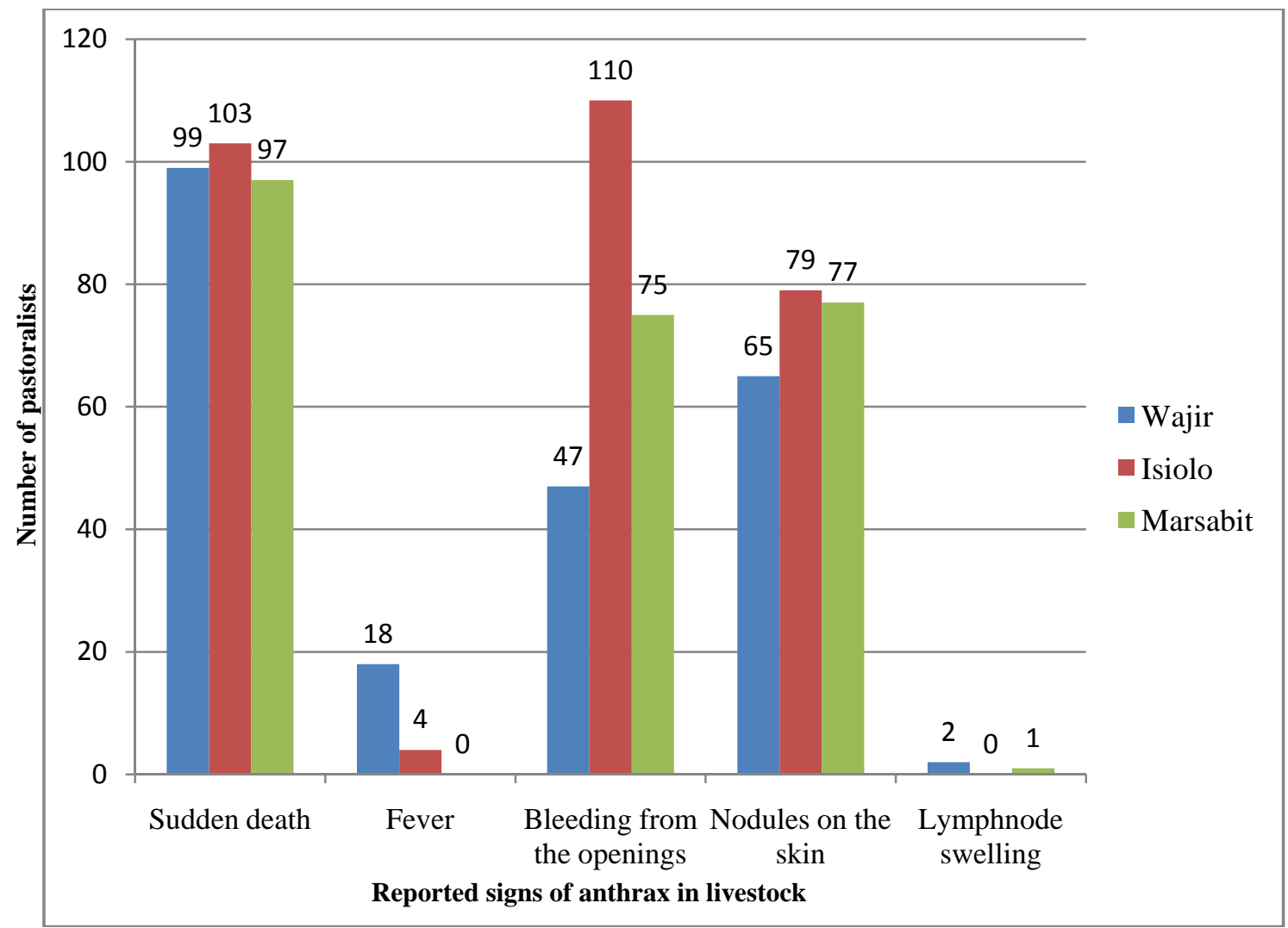

Fig. 2 Reported signs of anthrax in livestock by surveyed pastoralists of Wajir, Isiolo and Marsabit counties, Kenya. 


\section{Assessment of Knowledge, Attitude and Practices (KAPS) of Anthrax among Pastoralists in Wajir, Isiolo and Marsabit Counties, Kenya}

Table 5 Modes of anthrax transmission to humans reported by pastoralists from Marsabit, Wajir and Isiolo.

\begin{tabular}{lllllll}
\hline \multirow{2}{*}{ County } & \multicolumn{6}{c}{ Modes of transmission as perceived by the pastoralists } \\
\cline { 2 - 7 } & $\begin{array}{l}\text { Contact with } \\
\text { infected livestock }\end{array}$ & $\begin{array}{l}\text { Consumption of } \\
\text { infected products animals }\end{array}$ & $\begin{array}{l}\text { Contact with wild } \\
\text { aerosols }\end{array}$ & $\begin{array}{l}\text { Handlation of infected } \\
\text { carcass }\end{array}$ & $\begin{array}{l}\text { Skin of infected } \\
\text { animals }\end{array}$ \\
\hline Wajir & $24(12 \%)$ & $87(27 \%)$ & $4(5 \%)$ & $6(10 \%)$ & $81(31 \%)$ & $14(78 \%)$ \\
Isiolo & $95(48 \%)$ & $128(40 \%)$ & $26(32 \%)$ & $16(27 \%)$ & $80((31 \%)$ & $0(0 \%)$ \\
Marsabit & $80(40 \%)$ & $105(33 \%)$ & $52(63 \%)$ & $37(63 \%)$ & $98(38 \%)$ & $4(22 \%)$ \\
\hline Total & 199 & 320 & 82 & 59 & 259 & 18 \\
\hline
\end{tabular}

Table 6 Practices of pastoralists on dead animals and those who died specifically of anthrax.

\begin{tabular}{|c|c|c|c|c|c|c|}
\hline \multirow{2}{*}{ County } & \multicolumn{2}{|c|}{$\begin{array}{c}\text { Skinning dead animals } \\
\mathrm{n}(\%)\end{array}$} & \multicolumn{2}{|c|}{$\begin{array}{c}\text { Eating carcass from dead animal } \\
\mathrm{n}(\%)\end{array}$} & \multicolumn{2}{|c|}{$\begin{array}{c}\text { Eating animals dead for anthrax } \\
\mathrm{n}(\%)\end{array}$} \\
\hline & Yes & No & Yes & No & Yes & No \\
\hline Wajir & $0(0 \%)$ & 149 (100\%) & $0(0 \%)$ & 149 (100\%) & $0(0 \%)$ & $149(100 \%)$ \\
\hline Isiolo & 92 (63.4\%) & 53 (36.6\%) & 88 (60.7\%) & 57 (39.3\%) & $9(6.2 \%)$ & 136 (93.8\%) \\
\hline Marsabit & 105 (99.1\%) & $1(0.9 \%)$ & 105 (99.1\%) & $1(0.9 \%)$ & 73 (68.9\%) & 33 (31.1\%) \\
\hline Total & \multicolumn{2}{|c|}{400} & \multicolumn{2}{|c|}{400} & \multicolumn{2}{|c|}{400} \\
\hline
\end{tabular}

Table 7 Level of anthrax practices in Wajir, Marsabit and Isiolo counties.

\begin{tabular}{llll}
\hline Level of anthrax practice & Wajir & Marsabit & Isiolo \\
\hline Poor & $0(0 \%)$ & $72(67.9 \%)$ & $5(3.4 \%)$ \\
Moderate & $5(3.4 \%)$ & $33(31.2 \%)$ & $88(60.7 \%)$ \\
Good & $144(96.6 \%)$ & $1(0.9 \%)$ & $52(35.9 \%)$ \\
\hline Total & 149 & 106 & 145 \\
\hline
\end{tabular}

\subsection{Attitude of Anthrax by the Pastoralists}

Pastoralists had background knowledge about anthrax and they had gotten some traditional names for it as Table 3 shows. They had negative attitudes towards anthrax. They believed that anthrax was a very dangerous disease and affect both human and animals. Some of them believed that they should not talk about anthrax since this is a very serious disease. However, some pastoralists from Marsabit and Isiolo eat meat from animals that died of anthrax, they believed that cooking and throwing the intestines, soup and bones would protect them from getting anthrax infection.

Most farmers had negative attitude about anthrax vaccines, they believed that vaccines would not help their animals from the diseases but they later believed that anthrax vaccines reduced the occurrences of anthrax in Wajir, Isiolo and Marsabit counties, Kenya. As other pastoral community, some pastoralists from these three counties self-treated their animal against anthrax while some others choose wait and see attitude.

\subsection{Practices of Anthrax by Pastoralists}

On the handling of animal carcasses, respondents from Marsabit and Isiolo counties said they would skin the dead animals, eat the carcass or eat the carcass known to have died from anthrax (Table 6). None of the respondents from Wajir county responded to have engaged in these dangerous practices.

Regarding the anthrax practices, as Table 7 summarized, anthrax practices were good in Wajir (96.6\%). It was however poor (67.9\%) in Marsabit and moderate (60.7\%) in Isiolo.

\section{Discussion}

The present study provides preliminary baseline data regarding the knowledge, attitude and practices of anthrax by pastoralists. This opens the door for future contributions, research, surveillance and control efforts of anthrax in Kenya.

The level of education of the surveyed pastoralists 
was low. This was not surprising because pastoralists live in very remote areas where schools are non-existent and where present, they are few and far apart. These results are in agreement with the report of Kenya National Bureau of Statistics (KNBS) and Society for International Development (SID) [11] which documented similar poor education in Wajir and Marsabit counties. Lotira [12] also reported similar education levels of pastoralists in neighboring Turkana county. In Turkana, just like in the study counties, pastoralists practice nomadic pastoralism where they move over vast areas in search of water and pasture for their livestock. Thus it becomes difficult for the government to build permanent schools for their children; however for those pastoralists adopting a sedentary lifestyle, like in Kajiado county, education levels are higher.

The study revealed that anthrax was well known in the three study counties. Indeed, the pastoralists had local names for the disease mostly describing the manifestations of the disease (cutaneous, pulmonary and gastro-intestinal) or the source of the bacteria (soil). These results are consistent with those of Dharani et al. [13] who described an array of names given to anthrax by some pastoralists in Ethiopia, Uganda, Tanzania and Kenya. It has been shown severely that pastoral communities have a wealth of indigenous knowledge of diseases affecting their livestock. However and despite the indigenous knowledge, the training of pastoralists on anthrax awareness by conducted by local and international non-governmental organizations in the study counties may have played a part. In the purely agricultural county of Muranga, anthrax was well known just within the pastoral areas [14]. This may indicate that perhaps anthrax is known in most communities specially the sedentary counties in Kenya.

Despite the high levels of knowledge of anthrax by the study communities, they still engaged in dangerous practices that would put them at risk of exposure to the anthrax bacterium. These practices included skinning and opening suspect anthrax cases, consumption of meat from dead animals and even throwing carcasses into the bush. In Kenya, outbreaks of anthrax are into the attention of the authorities when people get sick and others die following the consumption of uninspected meat. The practice of boiling meat of suspect anthrax cases and throwing the soup severely is also practiced by the Turkana pastoral community. Whether this method of preparing suspect anthrax meat is effective is preventing infection with anthrax is a subject for further research. Similar poor husbandry practices regarding to anthrax were reported in Samburu county. In this county, some villagers butcher and consume the meat from infected carcasses. Others butcher, not for consumption but to feed their dogs with it. Still, in the absence of consumption by either humans or dogs, carcasses are normally opened before burial [10].

The practice of throwing instead of burning anthrax suspect cases into the bush is indeed dangerous. This would lead to the contamination of the environment with anthrax spores which would be aggravated by scavengers like vultures, hyenas, jackals. Once these spores are in the environment, they are known to remain viable for long periods of time, even up to 90 years [15] and therefore provide a source of future outbreaks. In Samburu community, the carcasses of diseased animal and the surrounding area are burned and the camps or manyattas are abandoned. Subsequently, the area will remain uninhabited for several years. All neighbouring manyattas are also moved far away [16]. There is a need to educate the pastoralists of the three study counties on the proper handling of anthrax/suspect cases of anthrax in livestock especially the need to bury them properly in the ground and importantly not to open such carcasses and consume the meat.

\section{Conclusions}

Anthrax was well known in the study community; however, the anthrax practices were poor. There were 


\section{Assessment of Knowledge, Attitude and Practices (KAPS) of Anthrax among Pastoralists in Wajir, Isiolo and Marsabit Counties, Kenya}

practices that were likely to cause infection or encourage the spread of anthrax spores in the environment such as eating of uninspected meat, opening of anthrax suspect carcasses and throwing of anthrax carcass in to the bush. These communities require continuous training programmes about the practices of anthrax and other zoonotic diseases. These can reduce the future occurrences of the disease in human wild life and domestic animals.

\section{Acknowledgments}

The authors would like to show their thanks to all people who extended their assistance during the data collection, analysis and manuscript writing. The findings and conclusions are those of the authors and do not represent the views of any other party.

\section{References}

[1] Andrews, A. H., Blowey, R. W., Boyd, H., and Eddy, R. G. eds. 2004. Bovine Medicine: Diseases and Husbandry of Cattle, 2nd ed. Blackwell Publishing Company.

[2] Fukao, T. 2004. "Immune System Paralysis by Anthrax Lethal Toxin: The Roles of Innate and Adaptive Immunity.” The Lancet Infectious Diseases 4 (3): 166-70.

[3] Boron, E. J., Peterson, R., and Finegold, S. M. 2002. Diagnostic Microbiology, 9th ed. Bailey and Scot's, 451-4.

[4] Santelli, E., Bankston, L. A., Leppla, S. H., and Liddington, R. C. 2004. "Crystal Structure of a Complex between Anthrax Toxin and Its Host Cell Receptor." Nature International Journal of Science 430: 905-8.

[5] Anna, R. S., and James, A. R. 2010. Emerging and Exotic Disease of Animals, 4th ed. Iowa State University.

[6] OIE. 2008. "Anthrax: Chapter 2.1.1 of OIE Listed Diseases and Other Diseases of Importance to International Trade.” OIE Terrestrial Manual, 135-44.

[7] Goossens, P. L. 2009. "Animal Models of Human Anthrax: The Quest for the Holy Grail.” Molecular
Aspects of Medicine 30: 467-80.

[8] Hartmut, K., Albert, W., Max, A., Burkhard, E., Henry, D., Hans, G., Werner, S., Alexander, V., and Horst, Z. 2003. Zoonoses: Infectious Diseases Transmissible from Animals to Human, 3rd ed. ASM Press.

[9] Munyua, P., Bitek, A., Osoro, E., Pieracci, E. G., Muema, J., Mwatondo, A., Kungu, M., Nanyingi, M., Gharpure, R., Njenga, K., and Thumbi, S. M. 2015. "Prioritization of Zoonotic Diseases in Kenya.” PLOS ONE 11 (8): e0161576. doi: 10.1371/journal.pone.0161576.

[10] Mathew, M., John, G., Athman, M., Isaac, L., Francis, G., Alice, B., Eric, O., Austine, B., Mwangi, S. T., Peninah, M., Harry, O., Njagi, O. N., Bernard B., and Njenga, M. K. 2018. "Recurrent Anthrax Outbreaks in Humans, Livestock, and Wildlife in the Same Locality, Kenya, 2014-2017.” American Journal of Tropical Medicine and Hygiene 99 (4): 833-9.

[11] Kenya National Bureau of Statistics (KNBS) and Society for International Development (SID). 2013. Exploring Kenya's Inequality, Pulling Apart or Pooling Together. A bridged report, KNBS, 1-56.

[12] Lotira, R. A. 2003. "Participatory Assessment of Livestock Marketing in Loima Division, Turkana District, Kenya.” MSc. thesis, University of Nairobi.

[13] Dharani, N., Yenesew, A., Aynekulu, E., Tuei, B., and Jamnadass, R. 2015. Traditional Ethnoveterinary Medicine in East Africa: A Manual on the Use of Medicinal Plants, edited by Dawson, I. K. The World Agroforestry Centre (ICRAF), Nairobi, Kenya, 86-9.

[14] Kioko, P. M. 2012. "Food Safety Knowledge and Practices among Actors in Beef Chain with Reference to Rift Valley Fever Outbreak in Maragua District, Kenya.” MSc. thesis, Kenyatta University.

[15] Radostits, O. M., Gay, C. C., Hinchchiff, K. W., and Constable, P. D. 2016. Veterinary Medicine: A Textbook of the Disease of Cattle, Horse, Sheep, Pigs and Goats, 11th ed. Saunders, 815-9.

[16] Muoria, K. P., Muruthi, P., Waititu, K., Boru, A. H., Mijele, D., and Oguge, N. O. 2007. "Anthrax Outbreak among Grevy’s Zebra (Equus grevyi) in Samburu, Kenya.” African Journal of Ecology 45 (4): 483-9. 